\title{
'Escalation of Commitment' as a Force for Good? Evidence from an Indonesian Digital Government Project
}

\author{
Muhammad Priandi \\ UNSW Sydney \\ m.priandi@unsw.edu.au
}

\author{
Walter Fernandez \\ UNSW Sydney \\ w.fernandez@unsw.edu.au
}

\author{
M.S. Sandeep \\ UNSW Sydney \\ ms.sandeep@unsw.edu.au
}

\begin{abstract}
In extant literature, 'escalation of commitment' is viewed as a recommitment of resources to a failing course of action that can lock projects into an ill-fated path of failure. This view portrays all feedback information driving recommitment decisions as "negative" in nature. In this paper we question this portrayal, joining an emerging alternative view that makes no assumptions about the nature of feedback. We take the view that feedback is inherently equivocal, and regard escalation of commitment as decision dilemmas arising out of such equivocality. Drawing on a case study of a digital government project in Indonesia, the paper explores this alternative view by understanding the antecedents of escalation of commitment deployed by key actors in steering a failing project to become a reasonably successful one. Theoretically, the paper suggests that the decision maker's dilemma is influenced by their personal beliefs, cultural norms and institutional values. The paper presents the notion of "perseverance of commitment", where escalation of commitment emerges, and is subsequently reinforced through a collective belief-driven reframing mechanism.
\end{abstract}

\section{Introduction}

The well-documented case of Project Taurus, an information systems (IS) project commissioned by the London Stock Exchange that collapsed after three years of intensive work and almost 500 million pounds of investment, is a somber reminder of organizations unable to stop from committing a series of disastrous decisions [1]. Although commitment to a strategy is important for successful execution of IS projects, it is often problematic when decision makers become overcommitted to a strategy which does not yield favorable outcomes. The problematic issue arises from an impression of "throwing good money after bad", by continuing allocation of resources to a course of action with little or diminishing chance of success [2]. This phenomenon of continuous or escalating commitment, where decision makers recommit resources to a failing course of action [3], has been an interest of management researchers for more than 40 years. The enduring interest, particularly in the field of IS project management, partly comes from the link between escalation of commitment and failing project situations as well as project outcomes [4]. Therefore, there is a significant body of work on escalation of commitment, which is extending our understanding on why and how this overcommitment happens in various contexts [5].

Early literature of escalation of commitment describe it as a "syndrome of decision errors" leading to a recommitment to a failing course of action. There are three elements of escalation of commitment: (a) a series of behaviors linking together as a course of action toward a goal-state; (b) feedback that the course of action is not achieving the goal-state (negative feedback); and (c) there is an opportunity for making decision on further allocation of resources to the same course of action [3]. "Decision errors" happens when decision makers continue the allocation of resource to a course of action despite the feedback that the course of action does not achieve the goal-state. Several theories of escalation offer explanations of such "decision errors" from the perspectives of psychological and social justification (self-justification theory) [6, 7], goal incongruency and information asymmetry (agency theory) [8], sunk cost (prospect theory) [9], and completion effect (approach avoidance theory) [10]. In this view of escalation of commitment as the result of decision errors, escalation is likely to make a failing project fail further unless escalation of commitment is interrupted or de-escalated, or the project is abandoned.

However, there is an alternative view of escalation of commitment, which challenges the assumption of reliability on "negative feedback" because reliable or complete information on the feedback or the outcome from a course of action may not always available to decision makers [11]. When feedback information is unreliable or incomplete, feedback becomes equivocal 
which leads to a possibility for having multiple interpretations of the feedback (negative, positive, or ambiguous). So, a failing course of action may still be perceived as having positive feedback. Bowen [11] suggests that escalation of commitment is a "decision dilemma", as decision makers continue the same course of action because that is the best option based on the equivocal feedback available to them. The consequence of equivocal feedback is that it is almost impossible to judge if escalation of commitment is an error because of the multiple interpretation of feedback. Another consequence is that escalation of commitment has the possibility for positive outcomes.

To summarize, most studies adopt the "decision errors" view of the phenomenon [see 12, 13]. In this view, positive outcome of escalation of commitment is unlikely. On the other hand, the "decision dilemmas" view suggest that it is possible for projects experiencing escalation of commitment to achieve their goal [11]. There is scarcity of research on escalation of commitment leading to positive outcomes, which motivates this study. Specifically, we aim to understand the antecedents of escalation of commitment deployed by key actors in steering a failing project to become a reasonably successful one. We attempt to uncover the antecedents of escalation of commitment by studying a case of a drifting IS project which is turned around back to its track with the help of escalation of commitment.

We conducted an in-depth exploratory case study at a digital government project in Indonesian central government. Using qualitative interpretive approach, our study revealed a process where escalation of commitment emerges, and subsequently is reinforced, through a belief-driven reasoning which is based on the assessment of situation of the project. We suggest a notion of "perseverance of commitment", which is a form of reasoned escalation of commitment. Our study makes a theoretical contribution to the body of work on escalation of commitment by highlighting the significance of contextual personal, institutional and cultural values in decisions dilemma leading to escalation.

\section{Escalation of commitment}

In its early studies, the commonly used definition for escalation of commitment (or "escalation") is the continued commitment in the face of negative information or feedbacks about prior course of action $[3,6,11]$. This situation is usually accompanied by uncertainty on the likelihood of goal attainment [6]. However, some studies on escalation of commitment challenge the significance of negative information or feedbacks $[8,9,11]$. Recent escalation of commitment studies adopts a relatively more generic definition, which is the act of committing additional resources to what appears to be a questionable or failing course of action [5]. While the concept of escalation is rooted in the field of social psychology [14], it has been studied in related fields such as project management and particularly in the context of IS project management [e.g., 15, 16].

\subsection{Major theories of escalation}

The first major theory of escalation is selfjustification theory, which is drawn from theory of cognitive dissonance [17]. The main premise of this theory is the unwillingness of individuals to admit that their previous decisions are failing. A lot of early studies adopted this view [e.g., 6, 7, 14] which set the reputation for self-justification theory as traditional explanation of escalation. Self-justification theory views escalation as driven by the need to demonstrate rationality of earlier decisions. By escalating their commitment, decision makers increase the effort for reaching designated goals so they can prove that their previous decision is correct, in other words "to make good on" prior investments [3].

Whyte [9] highlights that in some studies [e.g., 7, 14] the effects of negative feedback and personal responsibility are not consistent with self-justification theory. He proposed an alternative explanation based on prospect theory [18], where perceived outcome of earlier decision (i.e., success or failure) determines the framing of subsequent decision. With failing decision (negative framing of feedback), decision makers frame subsequent decision as a choice between losses. In that situation, decision makers tend to adopt risk seeking behavior, which leads to escalation. In short, escalation of commitment is the outcome of the manner that individuals frame decisions and subsequently choose between alternatives.

Approach-avoidance conflict can also lead to escalation [10]. Lewin [19] defined "approachavoidance conflict" as making decision on an action which has both positive and negative effects or characteristics. Decision of escalation bears negative effect in additional allocation of resource, which acts as restraining force. Despite that, there is a driving force in the chance of achieving the goal. Escalation is likely to happen when the cost of persistence on the same course of action is outweighed by the size of the reward for goal attainment, the cost of withdrawal, or the proximity to the goal. As perceived proximity to the goal increases, the motivation of individuals to achieve that goal also increases. This "completion effect" [20] then becomes a driver for escalation. 
Decisions dilemma theory argues that the concept of "negative feedback" is ill-defined [21] because researchers evaluate escalation of commitment in the context of researchers' own perception of negative feedback. That "negative feedback" is actually equivocal for decision makers [11]. Therefore, this theory challenges the view of escalation of commitment as decision errors or irrational reactions to negative feedback. Instead, decision on subsequent course of action is an interplay between individuals' degree of commitment to a previous course of action and perceived equivocality of feedback for that course of action. This theory illustrates escalation of commitment as following up on the existing commitment to previous course of action in the face of equivocal feedback. Equivocality of feedback incites a decision dilemma between staying in current course of action (escalation) or adopting a different course of action.

We have presented a brief overview of major theories of escalation of commitment (Table 1). To summarize, there are several views on the motivation behind escalation. Escalation has been explained as self-motivated action, or a decision between avoiding loss and going after gains. Escalation has also been viewed as reflection of past events, or anticipation of potential future outcomes. There is even a suggestion that escalation is basically a decision makers' response to equivocal information, manifesting in a decision dilemma.

\subsection{Escalation of commitment in IS studies}

IS studies on escalation exhibit similar pattern with overall pattern of research on escalation of commitment. For one, majority of those studies adopted laboratory experimentations in their research design. In addition to the resemblance in research design, IS studies on escalation also adopted many constructs from field studies outside IS, such as the effect of sunk cost [22], the framing of feedbacks [23], and performance appraisal [16]. Therefore, the contribution IS escalation studies mostly have been in generalization of these variables as antecedents of escalation in the field of IS.

However, there is a growing body of work in IS research that investigates the development of process theory for escalation of commitment. Some IS studies proposes process of escalation of commitment as stage or phase models [24]. Other studies describe process within escalation of commitment as a sequence of iterative events where actor-networks evolve [25] or opposing forces between pro and against persistence compete [26]. Some IS studies adopt the view that reversal of escalation or de-escalation as an exit strategy for escalation situation, and they investigate various strategy recommendations for de-escalation of commitment [12, 13]. Furthermore, IS scholars probe the connection between escalation of commitment with institutionalization [27], risk management [28], and defective whistleblowing [29].

\section{Research design}

We chose qualitative exploratory case study with interpretive approach [30] for our research method in developing theoretical understanding of escalation of commitment in a digital government project. Different theoretical views on escalation of commitment and diversity of contextual settings suggest that the phenomenon is not yet sufficiently theorized. Within this situation, exploratory case study is particularly suitable to propose new theoretical insights [31].

We adopted Grounded Theory Method (GTM), an inductive research method which can generate substantive theories that are grounded in empirical data

Table 1. Theories of escalation of commitment

\begin{tabular}{|c|c|c|c|c|}
\hline THEORY & $\begin{array}{l}\text { EXPLANATION } \\
\text { OF ESCALATION }\end{array}$ & $\begin{array}{c}\text { MAIN } \\
\text { CONCEPTS }\end{array}$ & $\begin{array}{l}\text { ASSUMPTION ON } \\
\text { FEEDBACK }\end{array}$ & $\begin{array}{l}\text { OUTCOME OF } \\
\text { ESCALATION }\end{array}$ \\
\hline $\begin{array}{l}\text { Self- } \\
\text { justification } \\
\text { theory }\end{array}$ & $\begin{array}{l}\text { Self-justification of } \\
\text { the correctness of an } \\
\text { earlier decision }\end{array}$ & $\begin{array}{l}\text { Psychological } \\
\text { and social self- } \\
\text { justification }\end{array}$ & \multirow{3}{*}{$\begin{array}{l}\text { Negative framing of } \\
\text { feedback (e.g., } \\
\text { overruns in project } \\
\text { time and budget, } \\
\text { design problems, user } \\
\text { resistance, } \\
\text { continuous changes } \\
\text { in user requirements) }\end{array}$} & \multirow{3}{*}{$\begin{array}{l}\text { Without an intervention } \\
\text { to stop the escalation of } \\
\text { commitment (i.e., new } \\
\text { course of action), the } \\
\text { expected outcome of } \\
\text { the escalation of } \\
\text { commitment is the } \\
\text { failure of the project. }\end{array}$} \\
\hline $\begin{array}{l}\text { Prospect } \\
\text { theory }\end{array}$ & $\begin{array}{l}\text { Risk-seeking behavior } \\
\text { in a losing situation }\end{array}$ & $\begin{array}{l}\text { Sunk-cost } \\
\text { effect }\end{array}$ & & \\
\hline $\begin{array}{l}\text { Approach- } \\
\text { avoidance } \\
\text { theory }\end{array}$ & $\begin{array}{l}\text { Forces driving } \\
\text { continued } \\
\text { commitment is } \\
\text { stronger than forces } \\
\text { for discontinuation }\end{array}$ & $\begin{array}{l}\text { Completion } \\
\text { effect }\end{array}$ & & \\
\hline $\begin{array}{l}\text { Decisions } \\
\text { dilemma } \\
\text { theory }\end{array}$ & $\begin{array}{l}\text { Ambiguous feedback } \\
\text { drives further } \\
\text { commitment }\end{array}$ & $\begin{array}{l}\text { Feedback } \\
\text { equivocality }\end{array}$ & $\begin{array}{l}\text { Feedback has } \\
\text { multiple } \\
\text { interpretation }\end{array}$ & $\begin{array}{l}\text { Outcome cannot be } \\
\text { determined prior to } \\
\text { escalation }\end{array}$ \\
\hline
\end{tabular}


from systematic exploration of a phenomenon [32]. The benefits of GTM for this study include the method's capacity to interpret complex phenomena through socially constructed experiences and processes [33], and its accommodation of social issues in discovering theory [32]. GTM is also suitable with the focus of this study in investigating a process [34].

\subsection{Case description}

DGIndo is a directorate general under a ministry in Indonesia. DGIndo is responsible for managing treasury and accounting of government financial transactions. It comprises of 33 regional offices and 181 field offices, serving more than 20,000 government working units throughout the country. As part of its initiative to modernize treasury and accounting of government financial transactions in Indonesian central government, DGIndo initiated two IS projects, Project N and Project S in 2007 and 2010, respectively. Project $\mathrm{N}$ is the implementation of a commercial off-the-shelf (COTS) enterprise resource planning (ERP) solution to replace the existing inhouse developed government treasury information system, which DGIndo uses to provide treasury services through all its regional and field offices. World Bank provided the grant to finance Project $\mathrm{N}$ as a multi-year project. On the other hand, the aim of Project $\mathrm{S}$ is to implement an integrated information system (hereafter "StarApp") for all government working units that is fully compatible with the new treasury information system which was implemented by Project N. Unlike Project N, Project S adopted inhouse development approach and was initially funded from state budget as single-year project. In this paper we focus on Project $\mathrm{S}$ as our study case. DGIndo considered StarApp as a significant and visionary breakthrough for government financial accounting in Indonesia. Prior to StarApp, government financial accounting system consisted of several standalone applications. Each handling certain function, i.e., budgeting, financial commitment, payment, inventory, fixed assets, treasury, and reporting. These application periodically shared data among each other through manual datafiles. This arrangement leads to issues of data inconsistencies and required processes of data reconciliation and compilation. From the beginning, DGIndo envisioned StarApp as an integrated solution with compatibility with internal (treasury ERP system) and external (e.g., bank, external organizations) information systems. The integrated design of StarApp also enables government working units to provide financial information and reports with improved data quality in near real-time. StarApp would also improve government's financial accountability and transparency through better data-sharing capability.

In the beginning, DGIndo set up Project $\mathrm{S}$ as a single fiscal-year project. It was not long before Project $\mathrm{S}$ underwent a lot of problems, leading to slow progress and missed milestones. At the end of 2011, StarApp failed the mandated user acceptance test (UAT) because it could not satisfactorily deliver several critical functionalities. The decision from UAT team was a "no-go", which means that StarApp needed further development before moving on to the next phase (i.e., piloting). However, being a single-year project, there was not enough time and funding to continue the necessary work. After securing another financing source, this time from a grant from the World Bank, the project continued in 2012. Progress was slow and StarApp did not pass user's acceptance test until 2014. The project was still slowly progressing when it began a three-stage piloting phase in 2015 . However, the progress rate of the project started to improve as it enters the last stage of piloting phase in 2017. By the year 2018, all government working units of DGIndo had fully replaced the old system with StarApp and Project S proceeded to roll-out phase for all other government working units.

The project team of Project $S$ initially consisted of a few personnel from development teams of previous treasury information systems, who were selected primarily based on their knowledge in existing systems. Later, the project recruited new personnel from DGIndo's regional and field offices, especially

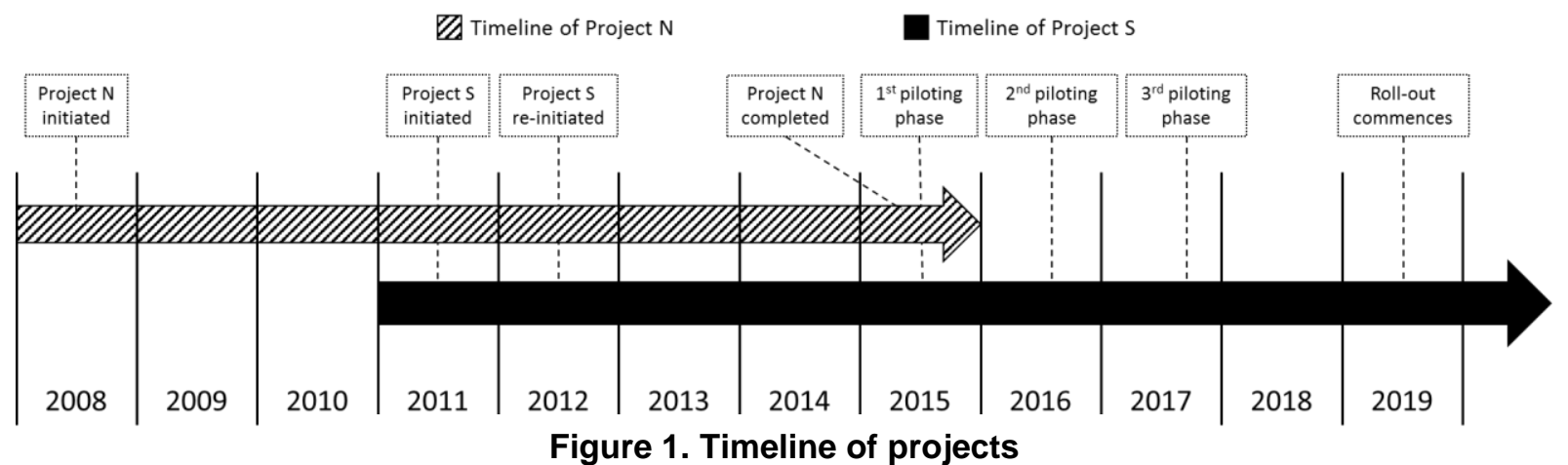


those with experience and skill in software programming. Members of Project $S$ are typically graduates from the state accounting academy, aged between mid-20s to mid-30s. The office of Project $S$ is in DGIndo headquarter in the capital city of Indonesia, where we conducted the fieldwork.

\subsection{Fieldwork}

Over a five-month period between June and November 2018, we visited DGIndo headquarter to collect data. In the beginning of our data collection, the initial aim was to understand the case and to identify major events. Given the interpretive approach of this study, we explored and analyzed the perspectives of members of project team on how the project evolved. We also attended and observed several activities such as project meetings, trainings of trainers, project meetings and project team's conference calls with DGIndo's field and regional offices as well as with end-users of StarApp. We were given a desk in DGIndo to work, with access to Project $S$ members workspaces. This access enabled us to have informal conversations with members of project team, and to have observations of daily operations of project team. We conducted semi-structured interviews with 11 individuals related to the project. (see Table 2). Interviews were conducted in local language (Bahasa Indonesia) to allow full expression from interviewees in their responses to our questions. We assured before each interview that we would keep the anonymity of all interviewees in any report that we might produce from this study. All interviewees gave their consent prior to each interview, which were digitally recorded and transcribed before then translated to English. Interviewees included former and current software programmers, project leaders, project managers, and a director. Most of the interviewees had worked on Project $S$ since the beginning of the project. All project members had been at DGIndo for more than 10 years.

The interviews began with a general question about interviewees role and responsibility in Project $S$, which was followed by an open discussion about their views on major events and challenges of the project and their involvement in those events. We also discussed their perceptions on the conclusions of those events and how those conclusions of events influenced the outcome of the project. In general, all interviewees spoke freely in our interviews, which was potentially in part because the first author was an employee of DGIndo, and all interviewees were professionally acquainted with the first author. In addition to interviews, we also collected secondary data from the DGIndo's official website and documentations, internal presentations, audio or video recordings from official meetings and project's YouTube channel.

We analyzed the notes from observations and informal conversations, as well as interview transcripts to identify themes. Following GTM, we initially approached data collection with a broad interest on how digital government project takes place in the context of developing countries. As our analysis progressed, we focused our investigation on the phenomenon of escalation of commitment after our analysis revealed that escalation of commitment is present as a phenomenon with significant importance in our case. Through this process, we identified themes relating to challenges during the implementation of Project $S$ and how members of the project team resolved those challenges. We coded these themes into three second-order concepts representing antecedents of escalation of commitment: "feedback from previous course of action", "leadership ambiguity" and "collective beliefs about work ethic".

Table 2. Summary of collected data

\begin{tabular}{|l|l|}
\hline \multicolumn{1}{|c|}{ Type of Data } & \multicolumn{1}{c|}{ Description } \\
\hline $\begin{array}{l}\text { Semi-structured } \\
\text { interviews }\end{array}$ & $\begin{array}{l}\text { 12 hours of audio interview } \\
\text { recordings with various } \\
\text { stakeholders, including the } \\
\text { managing director, project } \\
\text { managers, project procurement } \\
\text { officer, project leaders, software } \\
\text { programmers, software testers, and } \\
\text { business process officer. }\end{array}$ \\
\hline $\begin{array}{l}\text { Audio and } \\
\text { video } \\
\text { recordings }\end{array}$ & $\begin{array}{l}\text { Audio and video recordings of } \\
\text { project meetings, video conferences } \\
\text { with project stakeholders and } \\
\text { tutorial videos. }\end{array}$ \\
\hline $\begin{array}{l}\text { Organizational } \\
\text { documentation }\end{array}$ & $\begin{array}{l}\text { Official documents and internal } \\
\text { presentations }\end{array}$ \\
\hline $\begin{array}{l}\text { Publicly } \\
\text { available } \\
\text { materials }\end{array}$ & $\begin{array}{l}\text { IndoDG website, YouTube public } \\
\text { channel, and government } \\
\text { publications. }\end{array}$ \\
\hline
\end{tabular}

\section{Findings and analysis}

The empirical data showed that during the time Project $\mathrm{S}$ was under a lot of difficulties, particularly between 2012 until 2016, the project team continued their effort despite the lack of significant progress. We identified three main themes in our data, which are prominent in escalation of commitment in Project S. The first one is "feedback from previous course of action", which is in the center of decision making that triggers escalation. The other two themes are "leadership ambiguity" and "beliefs of good work ethic", both have influences in shaping the 
interpretation of feedback. Below, we present the analysis of our findings. We extend this analysis with discussion in the next section.

\subsection{Feedback from previous course of action}

Feedback from escalation of commitment, hereafter "feedback", refers to information on the outcome of a previous course of action. That feedback information reflects the performance of the previous course of action in reaching its goal state. Goal state refers to a desired end state from a course of action. In the case of escalation of commitment in Project $\mathrm{S}$, previous course of action refers to the decision to develop StarApp. The goal state of this course of action is "delivery of StarApp which can pass user acceptance test". Therefore, feedback in Project $S$ refers to all information that can be used to assess whether actions of Project $S$ bring it any closer to a delivery of StarApp that meets expected standards in user acceptance test.

Project $\mathrm{S}$ obtained feedback information via several methods. The first method was through reports of project management such as deliveries and milestones. Feedback information from this method suggested negative interpretation of Project $\mathrm{S}$ progress of action toward its goal-state. Project $S$ failed to meet its first deadline to pass user acceptance test in 2011. Later, Project $\mathrm{S}$ also progressed slowly for several years without being able to deliver the system.

The second method of obtaining feedback information was through subjective interpretation of surrounding environment by members of Project S. We found that feedback information from this method painted a more positive image of performance of Project S. For example, members of Project S assigned the perceived higher urgency of the parallel Project $\mathrm{N}$ as a temporary factor in slow progress of Project S. A project leader explained this view:

Because the magnitude of the project $\mathrm{N}$ was enormous, it was decided that Project $\mathrm{N}$ would go first until it settled, and after that we can focus on Project $\mathrm{S}$.

Another example of positive feedback information in Project $\mathrm{S}$ is the appreciation from stakeholders such as owners of business process. This appreciation may suggest that expectation on delivery of StarApp was still high. In words of a project leader:

With owners of business process, I think they responded positively. Although not as much as we hoped, at least we saw significant and active responses from key persons who oversaw decisions of policy in those units (owners of business process).
We found that feedback of previous course of action in Project $\mathrm{S}$ has characteristics of equivocal information. Information from formal assessments of project's progress in delivering acceptable output suggested negative interpretation of feedback. Yet, subjective assessment by project members of surrounding environment of the project hinted a positive interpretation of feedback. These multiple interpretations co-existed in the assessment of situation by Project S. Below we describe the other main themes, "leadership ambiguity" and "beliefs of good work ethic", which influence this equivocal feedback information.

\subsection{Leadership ambiguity}

The theme of "leadership ambiguity" refers to the uncertainties arising from conflicting messages in the actions of individuals in the top management of the organization. We observed two types of actions that members of Project $S$ perceived as signaling leadership ambiguity. The first one is "conflicting decisions" from individuals at different levels of DGIndo. The conflicting decisions appears to come from certain individuals who were not in full agreement with development of StarApp in favor of existing systems. Since these individuals were in middle level of management overseeing some members of Project $S$, they could give directives that in effect held back Project S. As illustrated by a project leader:

In terms of work, it's like there are two suns. [laugh] And where would they take us? Personally, we have no problem at all, but in terms of coordination it is rather difficult. The difficulty is because the instructions from each of them (in top management) are rather less conforming to each other. Ultimately, we ourselves got nothing to lose. We did not wish for anything, we only wished for clarity. The director ordered one thing but echelon 3 (officials who are directly below a director) did not give the same order. That is confusing. [laugh]

Another type of action is the lack of decision making, or "indecisiveness", that would help clearing up the uncertainty. By not making decisions to address "leadership ambiguity", the top management or leadership in DGIndo gave space to ambiguity to settle down in Project $\mathrm{S}$. This condition leads to a sense of frustration to members of Project $S$, as described by a project leader:

In my opinion, to work on two systems; the existing system, which is modified to resemble StarApp and the StarApp itself, requires an 
extraordinary amount of effort. Where do we want to go, really? That is all we want to know. If we want to go for StarApp, then let us focus on it. If not, then give us the order, 'okay StarApp is terminated, all of you can return to developing existing system'.

The leadership ambiguity has an effect of feeding on negative sentiments toward Project $\mathrm{S}$, such as confusion on the prospect of reaching the goal state of the project, and further frustration from the ongoing uncertainty. These negative sentiments boost negative interpretation of feedback information. Both the lingering confusion and the frustration in finding guidance for breakthrough, support a view that Project $\mathrm{S}$ was a lost cause.

\subsection{Collective beliefs about work ethic}

The theme of "collective work ethic beliefs" refers to a set of beliefs which are collectively held by members of Project $\mathrm{S}$. These sets of beliefs shaped the way Project $\mathrm{S}$ members processed feedback information in their reasoning for the decision to continue the project (escalation). Essentially, work ethic beliefs represent the view of what constitutes "good work ethos". For example, members of Project S believe that it is wrong to quit developing StarApp because that would be like abandoning their stakeholders, i.e., owners of business process and first adopters of StarApp. As a project leader described:

We have moral responsibilities. We do not want to be judged as opposing existing systems by supporting StarApp. But who will handle StarApp if we leave it, when it is still new? If there are people who can pick up our work, we would gladly hand it over. But if there is not, we would feel bad for our friends.

This work ethic belief, which resides at individual level, later emerged as collective beliefs in project level as individuals discovered that they share the same beliefs. We observed the collective nature of this belief from an incident when project members agreed on a collective action to bypass formal procedures so they can clarify the uncertainty related to their work with Project S.

There were nine of us, and we had discussion, and we agreed to send an email, on behalf of all of us, to all officers in our directorate. We explained that we were not asking anything for ourselves. But we were assigned here to secure the development of StarApp. We want to clarify our status, because we want to do well in our job.
The collective work ethic belief is further enforced by existent institutional values in DGIndo. DGIndo adopted a set of five institutional values from the ministry which is its mother organization. These institutional values are integrity, professionalism, synergy, service, and perfection. These values are widely promoted in the ministry as a set of good virtues that all employees should strive for. We noticed that some of these values were reflected in actions of project members, for example when a project leader spoke about "perfection" in his work:

I told to my friends, this is the problem here, this is the potential problems. We disclosed everything; everything should be thoroughly reviewed. No half-baked solutions. With halfbaked solutions there will be more troublesome later, we will be troubled by more testing.

The collective work ethic beliefs influence how Project S processes feedback information. Since work ethic beliefs, as well as extant institutional values, represent values of nobility and goodwill, they project positive sentiment toward the approach of Project $S$ in interpreting feedback information. In other words, work ethic beliefs enable Project $S$ to frame feedback in a more positive light, despite the negative effect from leadership ambiguity, which we have described in previous subsection.

Furthermore, we found some cultural norms exist in context Project $\mathrm{S}$, which help Project $\mathrm{S}$ to focus on positive interpretation. These cultural norms help members of Project $S$ in reconciling with negative effect from leadership ambiguity. For example, it is common in Indonesia to respect their elders or those who are older than themselves, and that respect is drawn from a common view that older people have more experience and thus possess wisdom. By adopting this cultural view, members of Project $S$ accept that despite projecting ambiguity, individuals in senior management has good intentions. As a project leader defended this view:

Back then, my superior officer had a different view from our managing director on developing StarApp. Yet, I felt like there was some truth in the argument of my superior officer, because it was based on his own experience. And we should not blame him, because personally he is a good man. I think if the purpose is good then there is no reason for him not to support StarApp. It's just that he has different background and that was what he thought was best, so that's why he did it (i.e., resisting Project S). And I think that is a reasonable dynamic [laughing]. 


\section{Discussion}

The above analysis shows the main themes of our findings which are related to antecedents of escalation of commitment. We present the overall process leading to escalation of commitment below (see Figure 2). We suggest a processual description of escalation of commitment in a project as the reframing of negatively distorted equivocal feedback information, which refocus the decision-making process to positive interpretation of the project.

We observed that multiple methods for assessing the situation of a project may result in feedback information with multiple interpretations (i.e., positive and negative interpretations) emanating from the previous course of action. This equivocal information sets up the beginning of decision-making dilemmas on whether to continue with the commitment to the project. The dubious nature of the equivocal feedback information makes it susceptible for amplification of either the positive or negative interpretations. Leadership ambiguity then amplifies the negative interpretation of feedback information, by feeding uncertainty and frustration to project members. Effectively, leadership ambiguity distorts the equivocal feedback information into a relatively more negative interpretation (see Figure 2).

The negatively distorted feedback information feeds into the reasoning process of the project to resolve the decision dilemma (of whether it should escalate their commitment on previous course of action), but at the same time, collective beliefs of work ethic provide positive influence to the same process (see Figure 2). Here, institutional values serve as promoters of goodwill which enforces work ethic beliefs. Culture of respect also feeds in further positivity to the reasoning process. The combined influence of collective work ethic beliefs, institutional values, and cultural norms of respect enable the project to focus on positive interpretation of feedback information. Essentially, the project's reasoning process acts to reframe the negatively distorted feedback information to a positive feedback, which justifies further commitment to the project (see Figure 2 ). We term this continued resilience in the face of negative distortion of feedback from leadership ambiguity as 'perseverance of commitment'.

Responding to scarcity of research on escalation of commitment leading to positive outcomes, our study suggests that escalation of commitment can help recovering a failing project by providing a mechanism of defense or survival for a project. Through escalation of commitment, even low-level members of a project can mount a defensive action in the face of leadership ambiguity. In the longer run, this entrenchment posture may help the survival of the project, by allowing a low or nonperforming project to continue until it reaches a more favorable performance. Finally, the emergence of escalation of commitment in our case study is characterized by drawing from collective beliefs, institutional values, and cultural norms to summon a positive interpretation of the feedback information. To that characterization, we posit this positive form of escalation of commitment as a form of perseverance. The concept of perseverance underlines the nature of continued resilience in the face of negative distortion of feedback from leadership ambiguity.

\subsection{Theoretical implications}

Building on the discussions above, we highlight several theoretical implications from our study, particularly in the context of digital government project of a developing country. First, our study provide empirical support for the view of escalation of commitment as "decision dilemma" [11]. Our study suggests that factors such as "leadership ambiguity" and "beliefs of good work ethic" may amplify the "decision dilemma". Second, while our study assumes the view of equivocal feedback information rather than

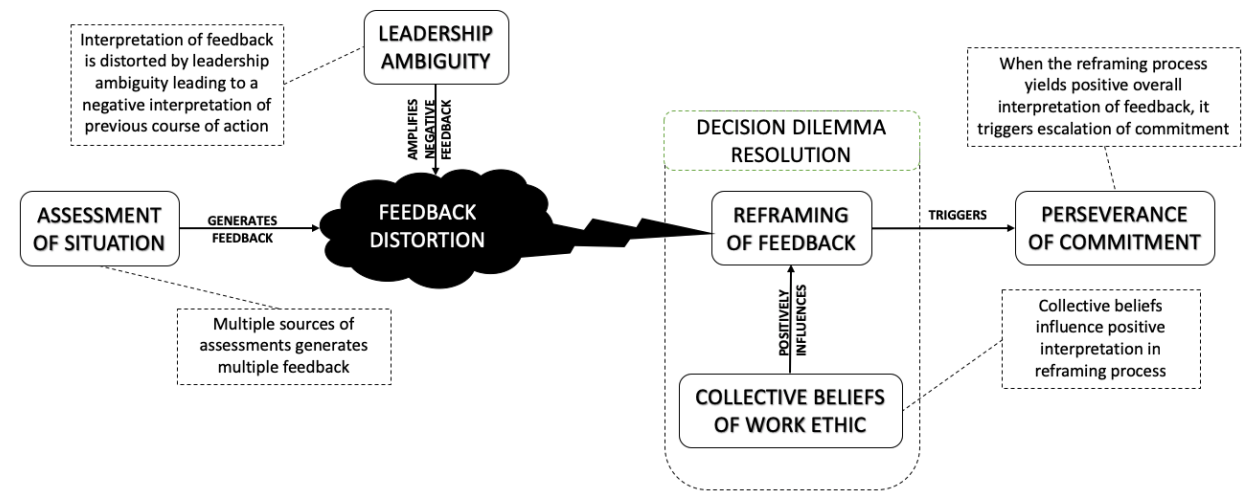

Figure 2. Model of perseverance of commitment 
a definite negative feedback, one can argue that reframing feedback is another form of self-justification $[6,7,14]$. In our study, reframing feedback serves as justification mechanism in rationalizing a negatively distorted feedback information. Third, the adoption of framing in our study highlight a resemblance to prospect theory [9], where negative framing of feedback leads to risk-seeking and escalation of commitment. However, we identified different role of framing, which is promoting positive interpretation to push for continuation of commitment. Fourth, our findings on the role of beliefs of good work ethic suggests that escalation of commitment as an issue of fulfilling certain behavioral standards and expectations. Following approach avoidance theory [10], we suggest that sustaining negative effect of leadership ambiguity as alternative view of "cost", and moral satisfaction from fulfilling beliefs of good work ethic as "reward". As such, our study may compliment approach avoidance theory in explaining escalation of commitment in government or public sector, where concepts of "cost" and "loss" are less tangible than in private sector. To sum up, our study suggests an alternative explanation of the process behind escalation of commitment by highlighting how various actors tap into the equivocality of feedback information, through either distortion or reframing of feedback.

\subsection{Practical implications}

The general view of escalation of commitment is unfavorable, especially with its association with conditions of a failing project. However, there is a scenario where escalation of commitment may have positive value through preservation in commitment. Practitioners might find this study useful in evaluating occurrences of escalation of commitment in their likely failing IS projects. This study can help IS project managers, especially in public sector of developing countries, to distinguish between 'positive' and 'negative' escalation of commitment based on characterization of ambiguity of management, prevalent collective value-set, and proximity between reasoning process for escalation and feedback information. Once managers identify the type of escalation of commitment, they can consider subsequent strategies between managing the perseverance of commitment or considering deescalation or reversal of escalation.

\section{Concluding remarks}

Despite general perception in literature that escalation of commitment is not good for the trajectory of projects, including IS projects, our study of a digital government project in Indonesia suggest that it may not always be the case. While some escalation studies have challenged the assumption behind escalation of commitment, our study takes a further step by understanding how escalation of commitment may not always be a questionable act but rather a force of good through a value-driven reasoning. Using military analogy with our study case, escalation of commitment rather acts as entrenchment strategy that serves as beachhead for turning a runaway project around toward the intended direction. Escalation of commitment may be successful when initiated from the segment of the project with value-driven individuals with good assessment of situation on the ground, followed by reiterated process that enables perseverance of commitment to grow into mobilization of support.

We acknowledge that this study has its limitation. The model is relatively a bird-eye view of the process behind escalation of commitment. We intend to extend our study by exploring further the reasoning mechanisms involved in our process model. The study is also based on one study case, therefore future similar studies in different context may improve or extend our model.

\section{Acknowledgments}

The authors would like to express their gratitude to the Indonesia Endowment Fund for Education (LPDP) for funding this research.

\section{References}

[1] Drummond, H., Escalation in Decision Making, The Tragedy of Taurus, Oxford University Press, Oxford, 1996.

[2] Lin, Y.-E., W.-M. Fan, and H.-H. Chih, "Throwing Good Money After Bad? The Impact of the Escalation of Commitment of Mutual Fund Managers on Fund Performance", Journal of Behavioral Finance, 2014, 15(1): p. $1-15$.

[3] Staw, B.M., "The Escalation of Commitment to a Course of Action". Academy of Management Review, 1981, 6(4): p. 577-587.

[4] Baghizadeh, Z., D. Cecez-Kecmanovic, and D. Schlagwein, "Review and Critique of The Information Systems Development Project Failure Literature: An Argument for Exploring Information Systems Development Project Distress", Journal of Information Technology, 2019.

[5] Sleesman, D.J., A.C. Lennard, G. McNamara, and D.E. Conlon, "Putting Escalation of Commitment in Context: A Multilevel Review and Analysis", Academy of Management Annals, 2018, 12(1): p. 178-207. 
[6] Brockner, J., "The Escalation of Commitment to a Failing Course of Action: Toward Theoretical Progress", Academy of Management Review, 1992, 17(1): p. 39-61.

[7] Staw, B.M. and J. Ross, "Commitment to A Policy Decision: A Multi-Theoretical Perspective", Administrative Science Quarterly, 1978, p. 40-64.

[8] Harrison, P.D. and A. Harrell, "Impact of "Adverse Selection" on Managers' Project Evaluation Decisions". Academy of Management Journal, 1993, 36(3): p. 635-643.

[9] Whyte, G., "Escalating Commitment to a Course of Action: A Reinterpretation", Academy of Management Review, 1986, 11(2): p. 311-321.

[10] Brockner, J. and J.Z. Rubin, Entrapment in Escalating Conflicts: A Social Psychological Analysis, Springer-Verlag, New York, 1985.

[11] Bowen, M.G., "The Escalation Phenomenon Reconsidered: Decision Dilemmas or Decision Errors?". Academy of Management Review, 1987, 12(1): p. 52-66.

[12] Pan, G. and S.L. Pan, "Transition to IS Project DeEscalation: An Exploration into Management Executives' Influence Behaviors", IEEE Transactions on Engineering Management, 2011, 58(1): p. 109-123.

[13] Mähring, M., M. Keil, L. Mathiassen, and J. Pries-Heje, "Making IT Project De-Escalation Happen: An Exploration into Key Roles". Journal of the Association for Information Systems, 2008, 9(8): p. 462-496.

[14] Staw, B.M., "Knee-Deep in The Big Muddy: A Study of Escalating Commitment to A Chosen Course of Action". Organizational Behavior and Human Performance, 1976, 16(1): p. 27-44.

[15] Keil, M., "Pulling the Plug: Software Project Management and the Problem of Project Escalation". MIS Quarterly, 1995, 19(4): p. 421-447.

[16] Lee, J.S. and M. Keil, "The Effects of Relative and Criticism-Based Performance Appraisals on Task-Level Escalation in an IT Project: A Laboratory Experiment". European Journal of Information Systems, 2018, 27(5): p. 551-569.

[17] Festinger, L., A Theory of Cognitive Dissonance, Vol. 2, Stanford University Press, 1957.

[18] Kahneman, D. and A. Tversky, "Prospect Theory: An Analysis of Decision Under Risk", in Handbook of the Fundamentals of Financial Decision Making, 1979, p. 99127.

[19] Lewin, K., "A Dynamic Theory of Personality", McGraw Hill, New York, 1935.

[20] Conlon, D.E. and H. Garland, "The Role of Project Completion Information in Resource Allocation Decisions". Academy of Management Journal, 1993, 36(2): p. 402-413.
[21] Northcraft, G.B. and G. Wolf, "Dollars, Sense, and Sunk Costs: A Life Cycle Model of Resource Allocation Decisions". Academy of Management Review, 1984, 9(2): p. 225-234.

[22] Keil, M., D.P. Truex, and R. Mixon, "The Effects of Sunk Cost and Project Completion on Information Technology Project Escalation", IEEE Transactions on Engineering Management, 1995, 42(4): p. 372-381.

[23] Liang, Ting-Peng, Nai-Shing Yen, Tsan-Ching Kang, and $\mathrm{Yu}-\mathrm{Wen} \mathrm{Li}$. "Escalation of Commitment in Software Projects: An Examination of Two Theories." Pacific Asia Conference on Information Systems, 2013, p. 44.

[24] Mähring, M. and M. Keil, "Information Technology Project Escalation: A Process Model", 2008, 39(2): p. 239272.

[25] Mähring, M., J. Holmström, M. Keil, and R. Montealegre, "Trojan Actor-Networks and Swift Translation: Bringing Actor-Network Theory to IT Project Escalation Studies". Information Technology \& People, 2004, 17(2): p. 210-238

[26] Pan, S.L., G.S.C. Pan, M. Newman, and D. Flynn, "Escalation and De-Escalation of Commitment to Information Systems Projects: Insights from A Project Evaluation Model", European Journal of Operational Research, 2006, 173(3): p. 1139-1160.

[27] Park, K.J. and N. Berente, "Institutionalization, Embedded Rationality, and the Escalation of Commitment to IT Projects", 45th HICSS, 2012.

[28] Parinyavuttichai, N. and A. Lin, "Reexamination of The Information Systems Project Escalation Concept: An Investigation from Risk Perspectives", in Strategic Project Management: Contemporary Issues and Strategies for Developing Economies, 2015, p. 179-202.

[29] Keil, M. and D. Robey, "Turning around Troubled Software Projects: An Exploratory Study of the Deescalation of Commitment to Failing Courses of Action", Journal of Management Information Systems, 1999, 15(4): p. 63-87.

[30] Myers, M.D., "Qualitative Research in Information Systems", MIS Quarterly, 1997, 21(2): p. 241-242.

[31] Yin, R.K., Case Study Research: Design and Methods. Fifth ed., Sage Publications Ltd., London, 2014.

[32] Glaser, B.G. and A.L. Strauss, The Discovery of Grounded Theory: Strategies for Qualitative Research, Routledge, 1967.

[33] Charmaz, K., Constructing Grounded Theory: A Practical Guide Through Qualitative Analysis, Sage, London, 2006.

[34] Creswell, J.W., Qualitative Enquiry and Research Design: Choosing Among Five Approaches. 2nd ed., Sage Publications, Thousand Oaks CA, 2007. 